\title{
Raising Teachers' Awareness of the Significance of Formulaic Sequences in Writing Proficiency
}

\begin{abstract}
:
In recent years, the academic arena witnessed a renewed interest in the role of vocabulary and with it the phenomenon of formulaic sequences (these are multi-word units which are stored and retrieved as whole from memory) came to the fore. Much research proved that these sequences are closely related to writing proficiency. In fact, several studies were carried out to investigate the use of formulaic sequences by language learners; however, investigating these sequences from the perspective of teachers was largely unexplored. Therefore, the present study attempted to explore English as a foreign Language (EFL) teachers' awareness of the formulaicity of language, their attitudes as well as practices regarding the incorporation of these sequences in writing classrooms. To achieve this purpose, a questionnaire was administered to 12 teachers of Written Expression at the department of English at Larbi Ben M'hidi University of Oum El Bouaghi. The obtained results showed the teachers' lack of awareness of the formulaicity of language. The study also revealed that though the teachers found formulaic sequences of high importance in improving writing proficiency and showed positive attitudes towards their inclusion in their writing classrooms, the instruction of these sequences was not really part of their teaching agenda.
\end{abstract}

Keywords: formulaic sequences, writing proficiency, awareness-raising, EFL teachers, attitudes

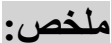

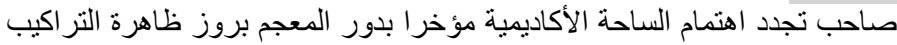

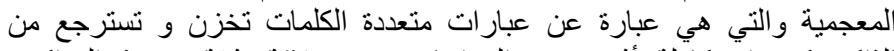

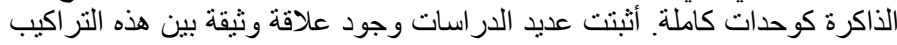

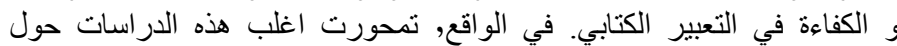

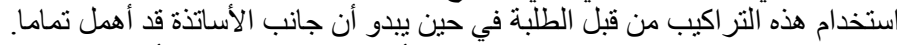

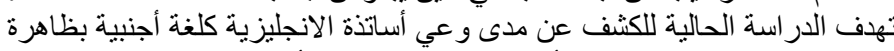

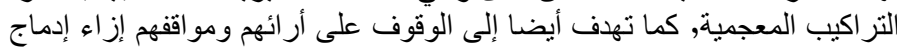

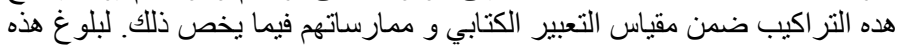

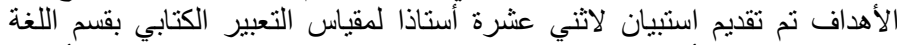

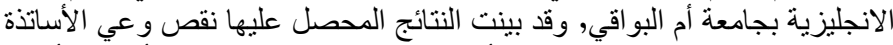

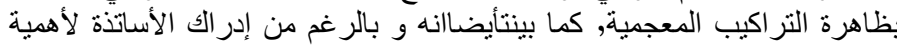

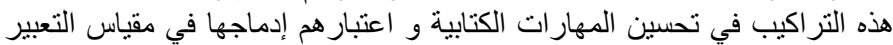

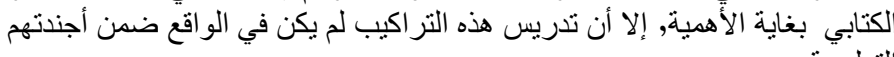

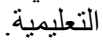

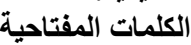
التراكيب المعجمية, الكفاءة الكتابية, التوعية, أساتذة الانجليزية كلغة أجنبية, المو اقف الثيب

\section{Khoualdi Safa}

Faculty of Letters and Languages Department of Foreign Languages

University of Mentouri

Constantine

\section{Introduction :}

${ }^{66}$ An essential property of language is that it provides the means for expressing indefinitely many thoughts and for reacting appropriately in an indefinite range of new situations" (Chomsky, 1965 , p. 6). Such was the view that many linguists had been wedded to for the past few decades. Language was thought to be highly creative in that a language user is able to produce and understand an infinite set of utterances that have never been met before (Wray, 2002). However, since the 1980's many linguists (e.g. Nattinger\&DeCarrico, 1992; Lewis, 1993; Wray, 2002) proposed that this view which depicts language as a process that involves the assembly of linguistic units according to syntactic rules has been over-exaggerated. 
Given the great number of utterances one might use to express an idea, why do native speakers limit themselves to certain expressions? For example, why is it correct to say "I want to marry you" and not "I wish to be wedded to you" or "I desire you to become married to me" (Pawley and Syder, 1983, p.196)? Why is it correct to say "to make a mistake" and not "to do a mistake"? The answer to such questions which were raised by Pawley and Syder (1983) and which they referred to as 'the puzzle of native-like selection' can be found in what many linguists (e.g. Wray, 2002; Schmitt, 2004; Wood, 2010) call formulaic sequences (FSs). These are multi-word units which are stored and retrieved from memory as whole for every recurrent situation (Wray, 2002). Therefore, from this point of view, much of the language native speakers use is prefabricated or ready-made rather than composed afresh each time it is used.

A growing body of research suggested that formulaic sequences play a key role in language development and production (Wood, 2002). This has significant implications for the foreign language classroom in which students' failure to produce appropriate language is ascribed to the lack or misuse of these sequences. Writing as a productive skill is still regarded as a headache maker by many language learners. The uneasiness felt when reading a student's paper and thinking "I know what you mean, but that's not the way to say it" (Lewis, 1997, p.259) is experienced by many teachers. Nevertheless, the disappointment teachers express in response to their students' written productions is a natural result of their own practices. The teaching practices of most English as a Foreign Language (EFL) teachers smack of the grammarlexis dichotomy. Many teachers have inculcated in the minds of their learners the idea that having wide grammar knowledge along with a sizeable pool of vocabulary words is the way to full mastery of the language (Lewis, 2000). Actually, it is this practice which makes learners prone to grammar mistakes for "they are using grammar to what it was never meant to do. Grammar enables us to construct language when we are unable to find what we want ready-made in our mental lexicons" (Lewis, 2000, p.15). Thus, much of the language used by proficient language users is prefabricated or formulaic.

Although the efficiency of incorporating FSs in second/foreign language writing classrooms was proved by many studies (e.g. Ohlrogge, 2009; Dai and Ding, 2010; Čolović-Marković, 2012), teachers' attitudes towards the inclusion of these sequences remained an uncharted territory. The focus has mostly been on the use of FSs from the perspective of learners. Therefore, the present study aims to bridge this gap by investigating Algerian EFL teachers' opinions and beliefs on the place of FSs in foreign language teaching as well as their attitudes and practices regarding their inclusion in writing classrooms. 


\section{Raising Teachers' Awareness of the Significance of Formulaic Sequences in Writing Proficiency}

questions:

More specifically, this study attempts to answer the following

1. Are EFL teachers aware of the phenomenon of formulaicity?

2. What are the teachers' attitudes and related practices regarding the inclusion of FSs in their writing classrooms?

\section{Literature Review}

\subsection{Definition of Formulaic Sequences}

Since formulaic language has been investigated and defined by many researchers, a plethora of terms have been coined to refer to it. Wray (2002) reported over fifty terms to describe this phenomenon. These include chunks, multi-word items/units, prefabricated patterns, lexical phrases, fixed expressions, lexical bundles to name just a few. However, in an effort to give some consistency to the field, various researchers (e.g. Wray, 2002; Schmitt and his colleagues (Schmitt, 2004); Wood, 2002, 2010) agreed on formulaic sequences as a coverall term for the multi-word units that appear in language. For Wray (2002, p.9), "formulaic carries with it some associations of 'unity' and of 'custom' and 'habit', while sequences indicates that there is more than one discernible internal unit".

Despite the debates raging back and forth over the phenomenon of formulaicity, there seems to be a certain amount of agreement on basic definitions of what makes FSs and what characteristics such sequences have in common that make them stand out (Wood, 2002). The agreement appears to be that "formulaic sequences are multi-word units of language which are stored in long term memory as if they were single lexical units" (Wood, 2002, p.2). This means that the words in a formulaic sequence are stored and recalled as one block rather than being generated from individual items and grammar rules anew each time they are used. In this regard, (Wray, 2002) observed that FSs are not always non-analyzable or non-compositional since some are composed out of their individual items and grammar rules, yet they become FSs through a process called fusion.

Moreover, corpus studies showed that FSs are not limited to such clear instances of multi-word units like idioms or proverbs and sayings (Schmitt \& carter, 2004). On the contrary, FSs entail a wide variety of multi-word items which can be diverse in terms of length, fixedness, lexical composition as well as function. These include, but are not restricted to collocations (e.g. strong coffee), social routine formulae (e.g. have a nice day), similes (e.g. clear as crystal), discourse devices (on the other hand), compounds (e.g. peer pressure), fillers (e.g. kind of), functions (e.g. would you please pass the $\mathrm{x}$ 'polite request') (Boers, Eyckmans, Kappel, Stengers, \&Demecheleer, 2006).

It has been calculated that FSs make $58.6 \%$ and $52.3 \%$ of spoken and written discourse (Erman\& Warren, 2000). Pawley and Syder (1983) even 
postulated that the number of multi-word units at the disposal of the mature native speaker amounts to hundreds of thousands. Hence, given the ubiquity of FSs in native speakers' discourse, many researchers (e.g. Nattinger\&DeCarrico, 1992; Lewis, 1993, 1997, 2000) argued for the significance of including them in English Language Teaching (ELT) methodology.

\subsection{The Importance of Formulaic Sequences in EFL Writing}

Most research studies focused on the role of FSs in spoken language (e.g. Pawley \&Syder, 1983; Wood, 2002, 2010; Boers et al., 2006). However, research is increasingly showing that FSs play a role in written language as significant as oral language. In this regard, Cowie (1992) observed that "it is impossible to perform at a level acceptable to native users, in writing or in speech, without controlling an appropriate range of multi-word units" (p.10).

The prime value of FSs lies in saving processing efforts which in turn aids fluent language production. An examination of the human memory system reveals that long term memory is characterized by an immense storage capacity. Short-term memory, on the other hand, is capable of processing only limited amounts of information. Therefore, it is efficient for the brain to summon FSs from long-term memory rather than take the burden of generating each sentence from scratch (Wei \& Ying, 2011). In this way, the brain saves time and attention is paid to other tasks. So, when these sequences are used repeatedly, they become a sign of fluent writing that meets the expectations of readers in academia (Coxhead\& Byrd, 2007).

In addition to fluency, FSs aid in achieving accuracy. Since FSs are retrieved as wholes from memory, they are more likely to reduce grammar errors and odd word combinations. Actually, these chunks serve as "'zones of safety' and appropriate use of them may thus confine the risk of 'erring' to the spaces in between the formulaic sequences in one's discourse" (Boers et al., 2006 , p. 247). Hence, by producing FSs as ready-made units, errors are reduced, native-like selection is attained and, at the same time, accuracy is achieved.

Formulaic sequences are also pragmatically effective in that they serve as discourse devices that guide the overall direction and organization of discourse. This type of sequences connect the meaning and structure of the discourse and signal relationships between previous and coming information, such as contrast (e.g. on the other hand, in contrast to), exemplification (e.g. for instance), addition (e.g. another thing is X) (Nattinger\&DeCarrico, 1992). In fact, the use of such devices is of great importance as they contribute to cohesion and coherence in written communication.

Last but not least, FSs can enhance the overall impression of learners' writing proficiency. Many studies proved that proficient writers tend to use 


\section{Raising Teachers' Awareness of the Significance of Formulaic Sequences in Writing Proficiency}

more FSs in their writing more than poor writers (e.g. Lewis, 2000; Ohlrogge, 2009).

This quick review reveals that FSs are the cornerstone of written language. As holistic units that can be retrieved from memory as wholes, FSs help language learners sound fluent, native-like, accurate and, therefore, come across as proficient writers. Therefore, since the use of these sequences is considered to be helpful in promoting writing proficiency, it follows that exposure to these sequences is of utmost importance especially for foreign language learners.

\subsection{The Necessity of Teaching Formulaic Sequences}

Given the importance attributed to FSs in written discourse, it stands to reason that they deserve a place in EFL writing classrooms. In this respect, Cowie (1992) observed, "clearly, the sheer density of ready-made units in various types of written text is a fact that any approach to the teaching of writing to foreign students has to come to terms with" (p.10). The pedagogical message of the necessity of devoting sufficient time to the explicit instruction of FSs has been conveyed to the teaching community (especially the EFL community) by many researchers (e.g. Lewis, 1993; Nattinger\&DeCarrico, 1992; Boers \&Lindstromberg, 2009). Lewis (1993), for example, focused on awareness-raising as the central tenet of his lexical approach. According to him, learners should be encouraged to notice language chunks inside and outside the classroom in order for them to acquire these sequences appropriately or as he put it " accurate noticing of lexical chunks ... help[s] convert input into intake" (Lewis, 1997, p. 53).

Other researchers went further when they suggested that mere noticing does not lead to the acquisition of these sequences. In a ten week study, Jones and Haywood (2004) highlighted FSs for students beginning a pre-sessional EAP course. The results showed that though the students' awareness increased, there was a slight improvement in the production of the sequences in a controlled situation (c-test) and no improvement at all in the use of these sequences in their essays.

Similarly, Boers and Lindstromberg (2009) argued that though useful as a first step, consciousness-raising and noticing are not enough to trigger the acquisition of FSs, which are complex in nature and thus challenging to most students. Many FSs are transparent that they may go unnoticed by most language learners; others are opaque which exerts a cognitive burden on the learners who will, in turn, try to ignore them. So, it goes without saying that the teachers are required to go far beyond helping students with the noticing of FSs as consolidating these sequences in memory is much more important.

Many studies cast light on the difficulties that challenge learners in their acquisition of FSs and the subsequent effect on their written productions. While 
Bolander (1989) reported an overuse of these sequences in the students' writing, Foster (2001) found an underuse. Likewise, Granger (1998) reported an underuse of the native-like sequences and an overuse of the foreign sounding ones. She also found a clear L1 interference in the use of these sequences. In this regard, Cortes (2004) observed that " it is possible that students were never explicitly instructed to use these target bundles when writing ..., and that is the reason why the use of these expressions is so rare in the students' corpora" (p.420).

In light of what has been said before, it is evident that it is the teacher's responsibility not just to raise students' awareness of FSs but also to help them commit these sequences to memory as they are the cornerstone of effective and fluent writing.

\section{Method}

\subsection{Population}

The participants of the present study were twelve (12) teachers of Written Expression at the department of English at Larbi Ben M'hidi University of Oum El Bouaghi, Algeria. Nearly all teachers (9) held a Magister degree, while three (3) of them had a $\mathrm{PhD}$ degree. The teachers had a teaching experience that ranged from 3 to 35 years (mean $=11.95$ years) and an experience with writing instruction that ranged from one semester to 25 years (mean $=6.45$ years). The fact that the writing experience level was much lower than the general teaching experience level could be accounted for by the fact that the teachers are not always assigned the module of Written Expression which is assumed to affect the students negatively.

\section{2. Data Collection Instrument}

As this study sought to investigate teachers' opinions and beliefs on the place of FSs in EFL writing classrooms as well as their related practices, a questionnaire was employed.

The questionnaire consisted of nineteen (19) multiple choice and openended questions that were organized into three sections. Section one concerned the academic background information of the participants. The questions were meant to provide information about the participants' qualifications, their experience with teaching at the university and with Written Expression instruction as well. The second section was about the writing skill and the role vocabulary in general and FSs in particular play in its improvement. The third and last section dealt with the teachers' attitudes towards the teaching of these sequences and their related practices.

\subsection{Results and Discussion}

Question 4: How would you rate your students' level in writing?

The teachers were asked about their students' level in writing by selecting from four options: very good, good, adequate, weak. Half of the 


\section{Raising Teachers' Awareness of the Significance of Formulaic Sequences in Writing Proficiency}

respondents (50\%) indicated that their students' level in writing was adequate while the other half $(50 \%)$ said that it was weak. Actually, this clearly shows that the teachers were not satisfied with their students' level of writing. As for the main reason behind their discontent, the next question would account for it.

Question 5: Why do your students fail to write appropriately?

The teachers were requested to pick out one option out of three offered to account for the major reason behind their students' weakness in writing. Table 1 below illustrates the obtained results.

\begin{tabular}{lc}
\hline Major Reason of Students' Weak Writing & Percentage \\
\hline They lack grammatical knowledge & $25 \%$ \\
They do not have the words & $16.66 \%$ \\
They have the words, but they do not know how to put & $58.33 \%$ \\
them together in chunks & \\
\hline
\end{tabular}

Table 1: The Main Reason behind Students' Weakness in Writing

Surprisingly, most teachers $(58.33 \%)$ said that their students fail to write appropriately mostly because they do not know how to put words together in chunks despite knowing the words that make up these chunks. Admittedly, we assumed that the highest percentage would go to lack of grammar knowledge followed by the poor repertoire of words as EFL teaching in our language classrooms is grammar-focused.

Question 6: Who is a proficient writer?

Three options were offered to the respondents to select from and more than one option could be opted for. The participants could also provide their own answers. The results are shown in table 2.

\begin{tabular}{lc}
\hline The proficient writer & Percentage \\
\hline The one who uses well chosen words & $16.66 \%$ \\
The one who generates sentences from scratch using & $50 \%$ \\
accurate grammar rules & $41.66 \%$ \\
The one who know how to put words together in chunks
\end{tabular}

\section{Table 2: Writing Proficiency}

As the table above shows, many teachers $(50 \%)$ thought that the use of accurate grammar rules to generate sentences anew is what makes writing proficiency. Actually, this result did not match the one in the previous question where just few teachers $(25 \%)$ said that the main problem with their students writing was the lack of grammar knowledge. This, in fact, confirms our assumption that teachers are still wedded to the view which accords grammar a centre stage position in the process of language learning/ teaching.

Moreover, $41.66 \%$ said that writing proficiency is the ability to put words together in chunks. Though this percentage is slightly lower than the one in the previous question (50\%), still it is considered high and it shows the teachers' awareness of the important role FSs play in building the writing skill. 
$58 \%$ of teachers added that writing proficiency is the use of good and organized ideas, a view that reflects the teachers' influence by the process approach which gives priority to the flow of ideas over the linguistic aspects.

The above results show that the participants had different views about what makes writing proficiency. As a matter of fact, writing proficiency could not be achieved through one of the above elements to the exclusion of the others. Rather, it is a multi-faceted concept in which all the mentioned elements are intertwined.

Question 7: How can writing proficiency be improved?

Three options were offered and the respondents could give their own answers.

\begin{tabular}{lc}
\hline The way to Improve Writing Proficiency & Percentage \\
\hline By teaching grammar & $8.33 \%$ \\
By teaching vocabulary & $0 \%$ \\
Both & $83.33 \%$ \\
\hline
\end{tabular}

Table 3: The Way to Improve Writing Proficiency

Nearly all teachers $(83.33 \%)$ said that the teaching of both grammar and vocabulary could improve writing proficiency. This means that the teachers knew that teaching grammar in combination with vocabulary helps learners improve their writing skill. It is worth noting, here, that grammar and vocabulary should not be treated as two separate divisions. The traditional belief has always been that "grammar is creative, while words are like building bricks, fixed packages of meaning" (Lewis, 1993, p. 37). However, the truth is that vocabulary and grammar represent a continuum rather than a dichotomy. Most English words whether lexical or grammatical cannot stand alone or convey meaning in themselves; rather they tend to combine with other surrounding words (Lewis, 1993). Therefore, teachers should treat grammar and vocabulary as one inseparable entity if their students are to achieve writing proficiency.

Additionally, five teachers (41.66\%) offered other suggestions on how to improve writing proficiency. They maintained that teachers of Written Expression should go far beyond the linguistic aspects to focus their attention on the teaching of the different writing techniques like coherence, organization, unity of ideas (3), and by assigning reading tasks (1) and teaching students the thinking skills (1). So far, it seems clear that the teachers are once again stressing the idea of moving away from the linguistic skills to give primacy to ideas and the different writing techniques. However, our assumption is that students especially at beginning level are unlikely to pay attention to ideas or other writing techniques if they have difficulties with the linguistic skills (vocabulary, grammar etc). Usually, the major concern of most EFL students is to produce an accurate piece of writing in the target language.

Question 8: What is your understanding of vocabulary? 


\section{Raising Teachers' Awareness of the Significance of Formulaic Sequences in Writing Proficiency}

As it was expected, nearly all teachers (11) think of vocabulary as the stock of single words that make up the language, which is probably what most people think as well. Though corpus linguistic research found evidence that words tend to co-occur with each other, teachers still hold the view that the word is the basic unit of meaning, a fact which is due to the teachers' influence by the view that considers grammar and vocabulary as two separate entities.

Question 9:Do you emphasize the role of vocabulary in your writing classrooms?

Nearly all teachers $(91,66 \%)$ stated that they emphasize the role of vocabulary in their writing classrooms. This implies that they knew the significance of this linguistic aspect in the writing process.

Question 10required the subjects who answered negatively $(8,33 \%)$ in the previous question to justify their answer. The teacher stipulated that he did not teach vocabulary because he was constrained by a program. In this regard, it should be noted that Written Expression is a complex skill that requires enough time so that teachers are able to cover the program without haste and work on all aspects that can be of help to their students to build their writing skill.

In question 11, the respondents were asked whether vocabulary should be taught through the other modules or should be dealt with separately. The question's aim was to find out the importance teachers assign to vocabulary instruction in their language classrooms. Most teachers $(66,66 \%)$ said that vocabulary should be taught through the other skills, while the remaining teachers $(33,33 \%)$ stated that it should be taught as a separate module. In fact, the obtained results came as no surprise as vocabulary has always been the Cinderella in our language classrooms. Most teachers still hold the view that vocabulary will take care of itself in the process of language learning. However, what these teachers seem to lose sight of is the fact that though incidental learning of vocabulary might be useful in some cases, it is not as effective as explicit learning as it is slow and rarely leads to retention let alone the carry-over to productive use. Therefore, it would be more effective if vocabulary is taught separately and explicitly to give learners the opportunity for efficient acquisition. Another question that obtrudes itself here is why is grammar not left to take care of itself?

Question 12: When you deal with vocabulary, do you focus on individual words, formulaic sequences, or both?

The overwhelming majority of teachers (75\%) said that they emphasize both FSs and single words when dealing with vocabulary, while the remaining teachers $(25 \%)$ stated that they focus on single words only. Actually, the obtained results did not seem to correlate with that of question 9 where nearly 
all teachers $(91,66 \%)$ equated vocabulary with single words. To shed more light on these contradictory answers, the next question will be analyzed.

Question 13: How do you teach new words?

Three choices were given and the participants were allowed to select more than one option. Table 4 below illustrates the obtained results.

\begin{tabular}{lc}
\hline Ways of Teaching New Words & Percentage \\
\hline In isolation & $0 \%$ \\
With the words surrounding them & $0 \%$ \\
In context & $83.33 \%$ \\
With the words surrounding them and in context & $16.66 \%$ \\
\hline
\end{tabular}

\section{Table 4: Ways of Teaching New Words}

As the table indicates, nearly all teachers $(83.33 \%)$ confirmed that they teach new words in context, while only two (16.66) said that they teach new words with the words surrounding them and in context. As a matter of fact, though most teachers were aware that words can better be learned when placed in context, many of them seemed to misunderstand the notion of contextualization. Actually, "contextualization means noting the situation in which the word may occur, but most importantly noticing the co-text with which it can regularly occur" (Lewis, 1993, p. 103). Besides, the obtained results leave no room for doubt that the discrepancies in the participants' answers were due to their unawareness of the formulaic nature of language despite claiming the opposite.

Question 14: How often do you draw your students' attention to formulaic sequences during your lessons?

This question seeks to investigate the teachers' practices with regard to the teaching of FSs in their writing classrooms.

\begin{tabular}{lc}
\hline Frequency of Drawing Students' Attention to FSs & Percentage \\
\hline Always & $25 \%$ \\
Often & $16.66 \%$ \\
Sometimes & $33.33 \%$ \\
Rarely & $8.33 \%$ \\
Never & $0 \%$ \\
\hline
\end{tabular}

Table 5: Frequency of Drawing Students' Attention to FSs

Of the total respondents, $33.33 \%$ reported that they draw their students' attention to FSs only sometimes, $25 \%$ said always; $16.66 \%$ stated that they do so often, against $8.33 \%$ who said rarely. The obtained results reveal that the teachers pay little attention to FSs teaching in their writing classrooms.

Related to the previous question, question 16 asked the teachers about the reason(s) for drawing their students' attention to FSs only sometimes or rarely. Three options were offered and the participants could give their own reasons. 


\begin{tabular}{lc}
\hline The reason(s) behind drawing students' attention to FSs only & percentage \\
sometimes or rarely & \\
\hline I do not have the time & $57.14 \%$ \\
I do not think it is useful & $0 \%$ \\
I do not know how & $0 \%$ \\
\hline \multicolumn{1}{c}{ Table 6: the Reason behind Drawing Students' Attention to FSs }
\end{tabular}
only Sometimes or Rarely

As the table shows, most teachers $57.14 \%$ (4) asserted that they pay little attention to FSs in their writing classes due to time constraints. As for the remaining three teachers $(42.85 \%)$, they gave different reasons. The first one said that because vocabulary is not taught as a separate module in our language classrooms, he had neither the time nor the intention to teach language chunks. He added that that he sometimes drew his students' attention to some words in context whenever possible. The second teacher maintained that the nature of the modules he taught did not allow him to deal with FSs, while the last one said that he drew his students' attention to FSs only when they were new to them.

As mentioned before, the module of Written Expression needs to be suitable to teachers and students alike both in terms of its contents and the time allocated to its teaching. Teachers should be given the chance to introduce anything that can help improve their students' writing proficiency without feeling the pressure of time or the crowded program. However, it is not right to just blame time constraints and the low status of vocabulary as the culprits that make the teaching of FSs a mission impossible. If teachers find enough time for drawing their students' attention to single words now and then, as the teacher stated above, they can do the same with FSs.

Questions 15 and 16 asked whether the participants think that mastering FSs helps students improve their writing proficiency, and if they agreed, in what ways they do so. The aim behind these two questions was to see if the teachers had a clear understanding of FSs and their role in promoting the writing skill. Interestingly, all the teachers agreed that FSs improve writing proficiency.

As for the ways in which FSs improve writing proficiency, the respondents reported that these sequences enhance and vary the students' writing style $(33,33 \%)$, make writing more accurate and native- like $(33,33 \%)$, decorate the text $(8,33 \%)$ and make students' papers comprehensive and effective $(16,66 \%)$. The remaining teacher just stated that these sequences are important. Obviously, the teachers' comments touched on some of the key 
benefits that FSs contribute to writing proficiency; nevertheless, most of them were superficial and did not give much detail on how these sequences improve the writing style or make writing more effective.

Questions 17 and 18 asked whether FSs should be incorporated in EFL classrooms and required the teachers to justify why they should or should not be included. Nearly all teachers $(91.66 \%)(n=11)$ agreed that FSs should be incorporated in language classrooms against only one (8.33\%) who responded negatively. They maintained that these sequences deserve to be taught since they form part of language vocabulary the same as single words (4) and help students with their writing skill (3). Besides, FSs not only promote the productive skills but also the receptive ones as well (3). The remaining teacher merely said that they should be included. The above comments lead us to say that the participants have a clear understanding of the role of FSs in language proficiency and hence positive attitudes towards their teaching.

As for the participant who responded negatively, he stipulated that the teacher in the classroom is constrained by time and by the objective of achieving communicative competence. Thus, it is the students' responsibility to acquire these sequences on their own through extensive reading. Surprisingly, this participant seemed to have unclear understanding of what makes communicative competence. Widdowson illustrated that "communicative competence is not a matter of knowing rules .... It is much more a matter of knowing a stock of pre-assembled patterns, formulaic frameworks" (1998, p. 135). Besides, it is illogical to think that learners can acquire these sequences incidentally through extensive reading because it is assumed that learners are not even aware of the existence of these sequences; so, how can they acquire or even notice them?

In question 19, which is the last one, the subjects were asked whether they were interested in incorporating FSs in their classrooms to help students write proficiently. The majority of teachers $83.33 \%(\mathrm{n}=10)$ said that they were interested in teaching FSs to help their students write better, while the remaining two teachers $(16.66 \%)$ responded negatively. The obtained results are, in fact, encouraging as they showed the teachers' willingness to teach FSs as long as they think they are helpful for their students' writing.

\section{Conclusion}

The central issue addressed in this study is the place FSs hold in EFL classrooms. More specifically, a questionnaire was designed to investigate teachers' awareness, attitudes as well as their practices regarding the teaching of these sequences in their writing classrooms.

The obtained results revealed that teachers still treat language as a composition of grammar and vocabulary items. Most of them still believe that vocabulary does not deserve their full attention and learners will acquire it on their own in the process of learning the other skills. Besides, though the 


\section{Raising Teachers' Awareness of the Significance of Formulaic Sequences in Writing Proficiency}

teachers claimed to emphasize both single words and multi-word units in their teaching, it seemed that they did not have these sequences in mind only when asked explicitly about them, the fact which can be attributed to their unawareness of the formulaic nature of language. Another significant finding of this study was the fact that though teachers found FSs of vital importance in improving students' writing proficiency and showed positive attitudes towards their incorporation in their writing classrooms, they were actually not paying enough attention to their teaching.

Therefore, the above results lead us to say that a change of mind-set on the part of teachers is a useful first step. As vocabulary is gaining more and more attention and the importance of FSs is widely recognized, teachers should jump on the bandwagon and help their learners acquire these sequences to make them achieve the proficiency level they aspire to.

\section{References:}

Boers, F., Eyckman, J. Kappel, J. Stenger, H., \&Demecheleer. (2006). Formulaic sequences and perceived oral proficiency: Putting a lexical approach to the test. Language Teaching Research, 10 (3), 245-261. doi: 10. 1191/13621688061r195oa

Boers, F., \&Lindstromberg, S. (2009). Optimizing a lexical approach to instructed second-language acquisition. London, England: Macmillan.

Bolander, M. (1989). Prefabs, patterns and rules in interaction? Formulaic speech in adult learners' L2 Swedish. In K. Hyltenstan\& L. K. Obler (Eds.), Bilingualism across the lifespan: Aspects of acquisition, maturity, and loss (pp. 73-86). Cambridge, NY: Cambridge University Press.

Chomsky, N. (1965). Aspects of the theory of syntax. Cambridge, MA: M. I. T. Press.

Čolović-Marković, J. (2012). The effects of explicit instruction of formulaic sequences on second-language writers (Unpublished doctoral dissertation). The niversity of Utah, The United States.

Cortes, V. (2004). Lexical bundles in published and student disciplinary writing: Examples from history and biology. English for Specific Purposes, 23, 397-423. doi: 10.1016/j.esp.2003.12.001.

Cowie, A. P. ( 1992). Multiword lexical units and communicative language teaching. In P. J. L. Arnaud \& H. Béjoint (Eds.), Vocabulary and applied linguistics (pp.1-12). London, England: Macmillan.

Coxhead, A. \& Byrd, P. (2007). Preparing writing teachers to teach the vocabulary and grammar of academic prose. Journal of Second Language Writing, 16, 129-147. doi: 10.1016/j.jslw.2007.07.002.

Dai, Z. \& Ding, Y. (2010). Effectiveness of text memorization in EFL learning of Chinese students. In D. Wood (Ed.), Perspectives on formulaic 
language: Acquisition and communication (pp. 71- 87). London, England: Continuum.

Erman, B. \& Warren, B. (2000). The idiom principle and the open choice principle. Text, 20 (1), 29-62.

Foster, P. (2001). Rules and routines: A consideration of their role in the task based language production of native and non-native speakers. In M. Bygates, P. Skehan, \& M. Swain (Eds.), Researching pedagogic tasks: Second language learning, teaching and testing (pp. 75-93). Harlow, England: Pearson.

Granger, S. (1998). Prefabricated patterns in advanced EFL writing: Collocations and formulae. In A. P. Cowie (Ed.), Phraseology: Theory, analysis, and applications (145-160). Oxford, NY: Oxford University Press.

Jones, M. \& Haywood, S. (2004). Facilitating the Acquisition of formulaic sequences: An exploratory study in an EAP context. In N. Schmitt (Ed.), Formulaic sequences: Acquisition, processing and use (pp. 269-292). Amsterdam, The Netherlands: Benjamins.

Lewis, M. (1993). Thelexical approach: The state of ELT and a way forward. Hove, England: Language Teaching Publications.

Lewis, M. (1997). Pedagogical implications of the lexical approach. In J. Coady\& T. Huckin (Eds.), Second language vocabulary acquisition: A rationale for pedagogy (pp. 255-270). Cambridge, England: Cambridge University Press.

Lewis, M. (Ed.). (2000). Teaching collocations: Further developments in the lexical approach. Hove, England: Language Teaching Publications.

Nattinger, J. R. \&DeCarrico, J. S. (1992). Lexical phrases and language teaching. Oxford, England: Oxford University Press.

Ohlrogge, A. (2009). Formulaic expressions in intermediate EFL writing assessment. In R. Corrigan, E. A. Moravcsik, H. Ouali, \& K. M. Wheatley (Eds.), Formulaic language: Acquisition, loss, psychological reality, and functional explanations (Vol. 2, pp. 375-386). Amsterdam, The Netherlands: Benjamins.

Pawley, A., \&Syder, F. (1983). Two puzzles for linguistic theory: Native-like selection and native-like fluency. In J. Richards, \& R. Schmidt ( Eds.), Language and communication (pp. 191-226). London, England: Longman.

Schmitt, N. (Ed.) (2004). Formulaic sequences: Acquisition, processing and use. Amsterdam, The Netherlands: Benjamins.

Schmitt, N. \& Carter, R. (2004). Formulaic sequences in action: An introduction. In N. Schmitt (Ed.), Formulaic sequences: Acquisition, processing and use (pp.1-22). Amsterdam, The Netherlands: Benjamins.

Wei, L. \& Ying, H. (2011). On the role of formulaic sequences in second language acquisition. US-China Foreign Language, 9 (11), 708-713. 
Raising Teachers' Awareness of the Significance of Formulaic Sequences in Writing Proficiency

Widdowson, H. G. (1989). Knowledge of language and ability for use. Applied Linguistics, 10 (2), 128- 137.

Wood, D. (2002). Formulaic Language in Acquisition and Production: Implications for teaching. TESL Canada Journal, 20 (1), 1-15.

Wood, D. (2010). Formulaic Language and second language speech fluency: Background, evidence and classrooms applications. London, England: Continuum.

Wray, A. (2002). Formulaic language and the lexicon. Cambridge, England: Cambridge University Press. 